\title{
Supplementary material to "The unidentified volcanic eruption of 1809: why it remains a climatic cold case"
}

Claudia Timmreck ${ }^{1}$, Matthew Toohey ${ }^{2}$, Davide Zanchettin ${ }^{3}$, Stefan Brönnimann ${ }^{4}$, Elin Lundstad ${ }^{4}$, and Rob Wilson ${ }^{5}$

${ }^{1}$ The Atmosphere in the Earth System, Max Planck Institute for Meteorology, Bundesstr. 53, 20146 Hamburg, Germany

${ }^{2}$ Department of Physics and Engineering Physics, University of Saskatchewan, Saskatoon, Canada

${ }^{3}$ Department of Environmental Sciences, Informatics and Statistics, University Ca' Foscari of Venice, Mestre, Italy

${ }^{4}$ Institute of Geography Climatology and Oeschger Centre for Climate Change Research, University of Bern, Bern,

Switzerland

${ }^{5}$ School of Earth \& Environmental Sciences, University of St. Andrews, United Kingdom

Correspondence: Claudia Timmreck (claudia.timmreck@mpimet.mpg.de)

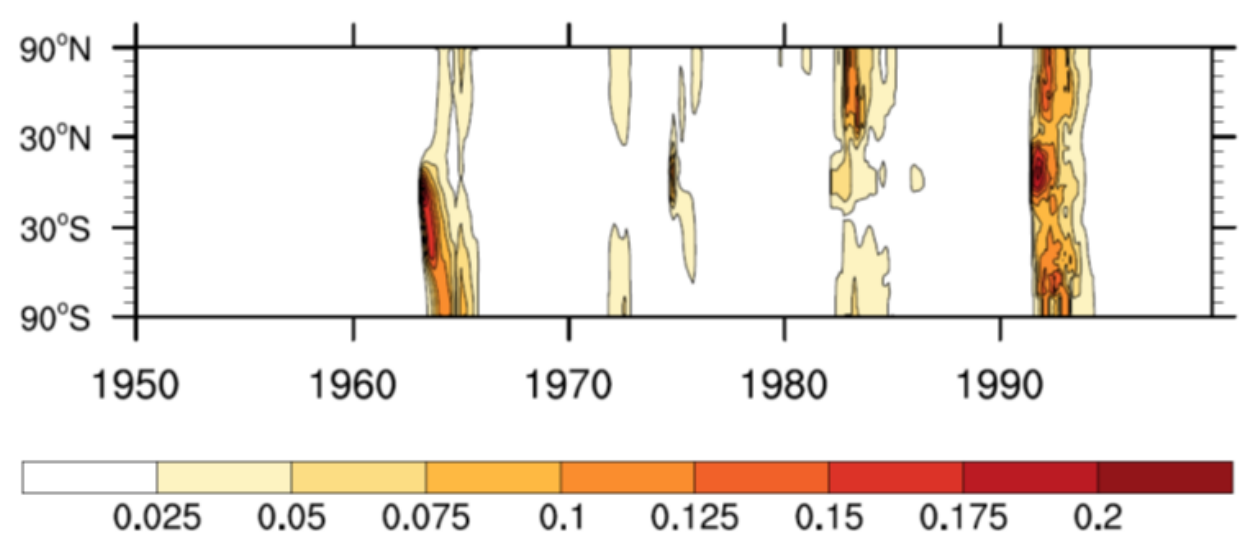

Figure S1. Global stratospheric aerosol optical depth (SAOD) at $0.55 \mu \mathrm{m}$ as provided in CMIP6 based on the Global Space-based Stratospheric Aerosol Climatology (GLOSSAC, Thomason et al., 2018). 

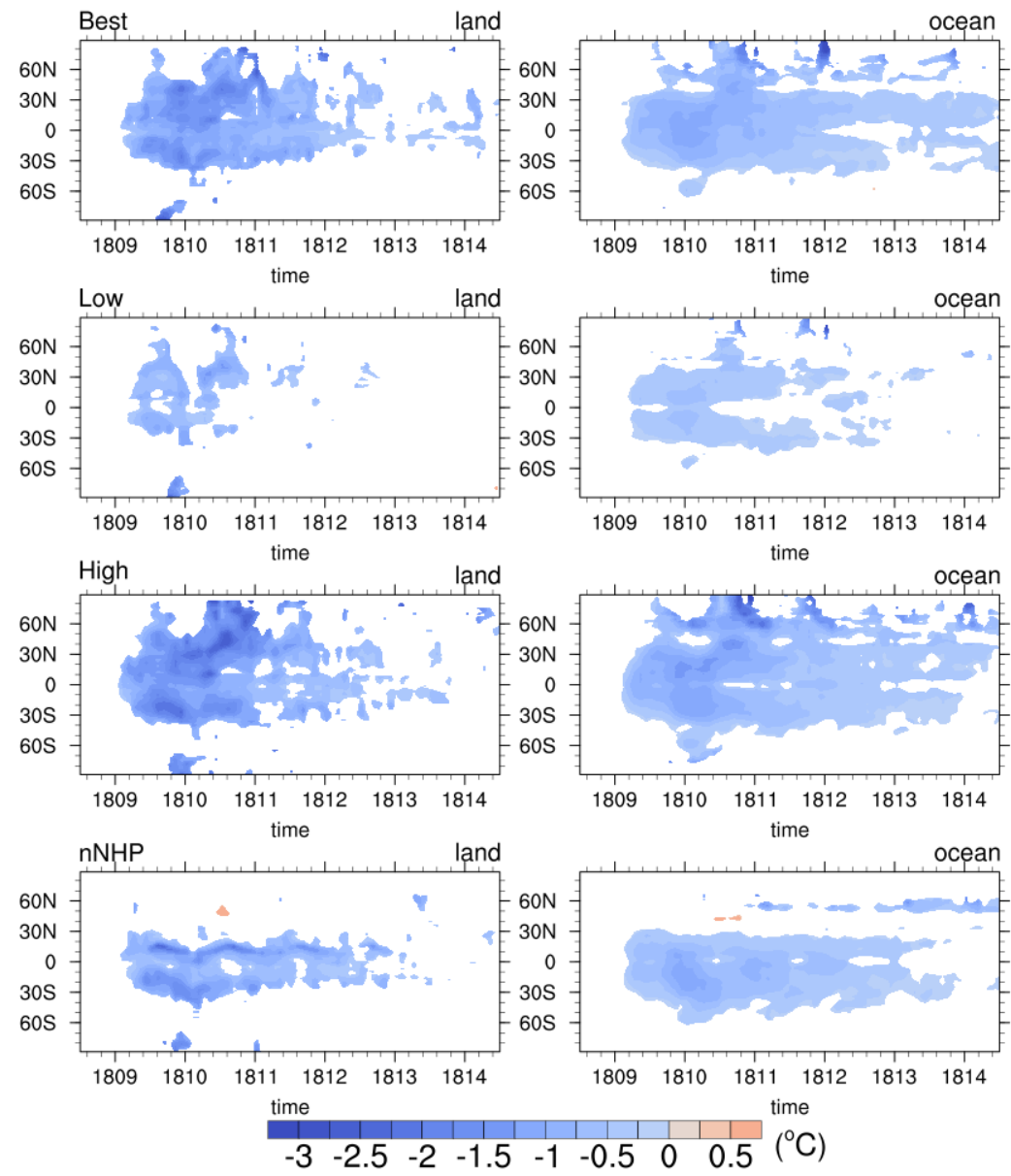

Figure S2. Simulated ensemble mean zonal mean near-surface air temperature anomalies $\left({ }^{\circ} \mathrm{C}\right)$ for the Best, Low, High and nNHP scenarios. Left panel: land right: ocean. Only those anomalies are shown which exceed one standard deviation of the control run. Anomalies are calculated with respect to the 1800 to 1808 mean. 

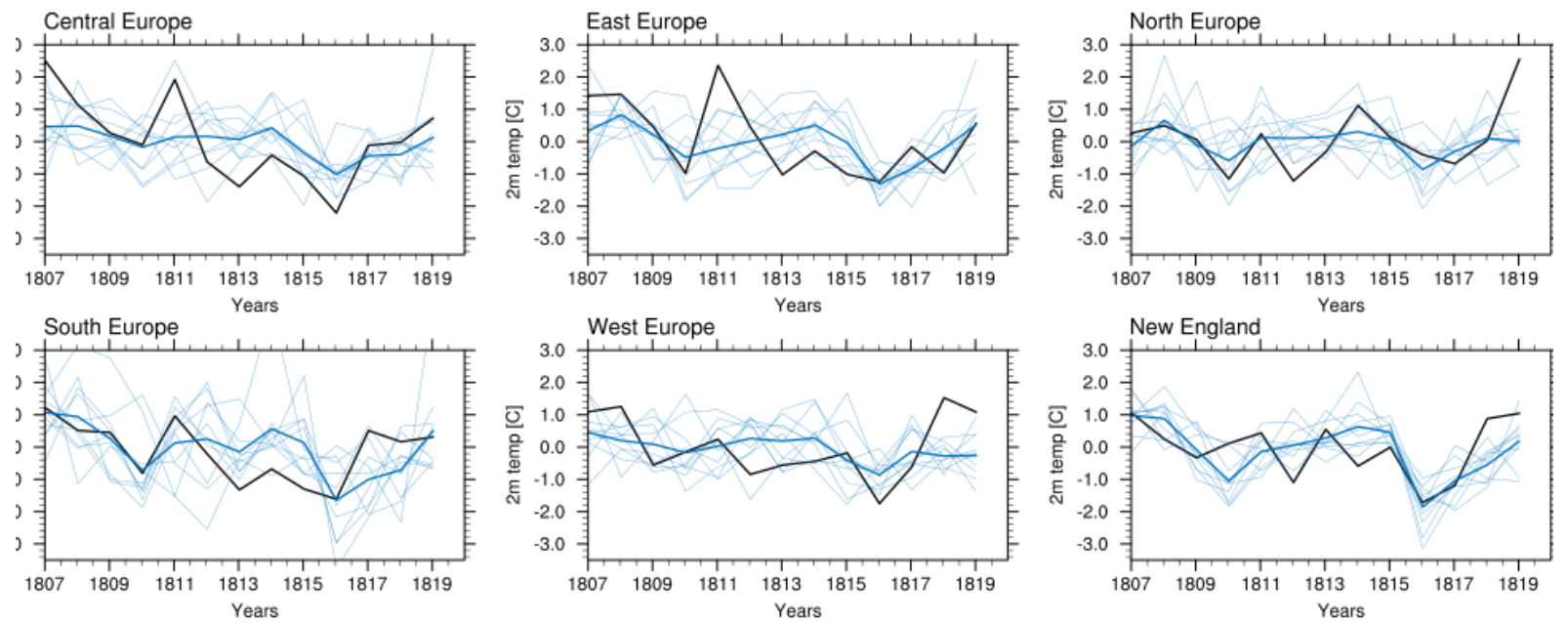

Figure S3. Monthly mean near-surface summer temperature anomalies $\left({ }^{\circ} \mathrm{C}\right)$ over different European regions $\left(\right.$ Central Europe $\left(46.1-52.5^{\circ} \mathrm{N}\right.$, 6-17.8 ${ }^{\circ}$ E), Eastern Europe $\left(47-57^{\circ} \mathrm{N}, 18-32^{\circ} \mathrm{E}\right)$, Northern Europe $\left(55-66^{\circ} \mathrm{N}, 10-31^{\circ} \mathrm{E}\right)$, Southern Europe $\left(38-46^{\circ} \mathrm{N}, 7^{\circ}-13.5^{\circ} \mathrm{E}\right), \mathrm{Western}$ Europe $\left(48.5-56^{\circ} \mathrm{N}, 6^{\circ} \mathrm{W}-6^{\circ} \mathrm{O}\right)$ and New England $\left(41-44^{\circ} \mathrm{N}, 73-69^{\circ} \mathrm{W}\right)$. The black line represents observations, the thick colored line the ensemble mean of the Best simulations, the thin lines the individual ensemble members. Anomalies for model and station data are with respect to the seasonal mean between 1806 and 1820 .
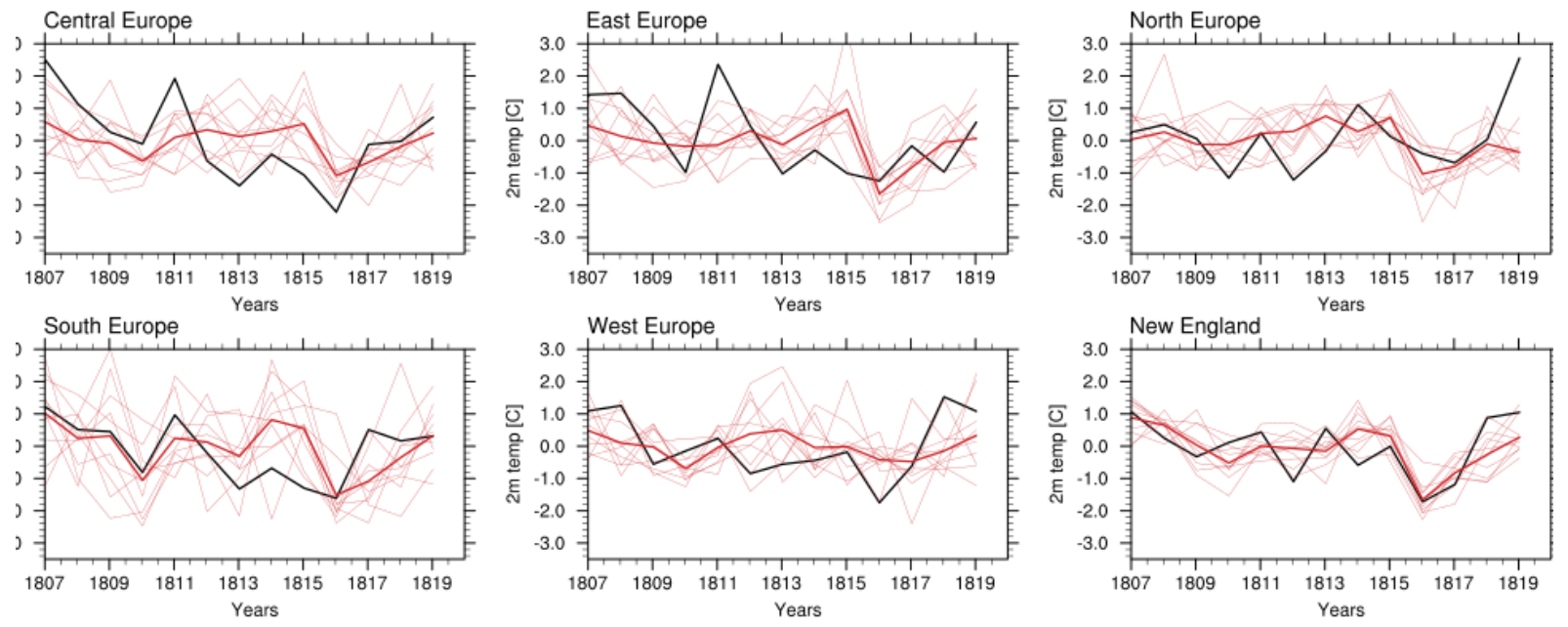

Figure S4. Same as Figure S3 but for Low. 

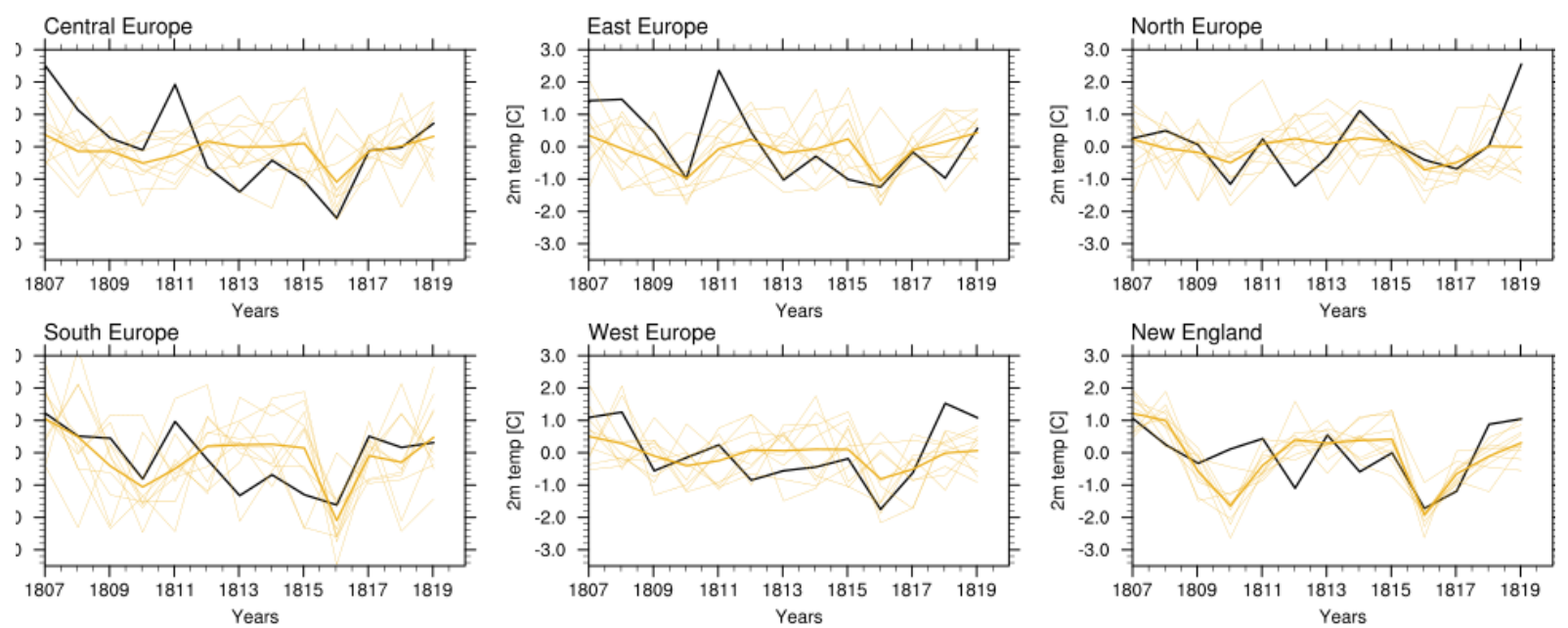

Figure S5. Same as Figure S3 but for High.
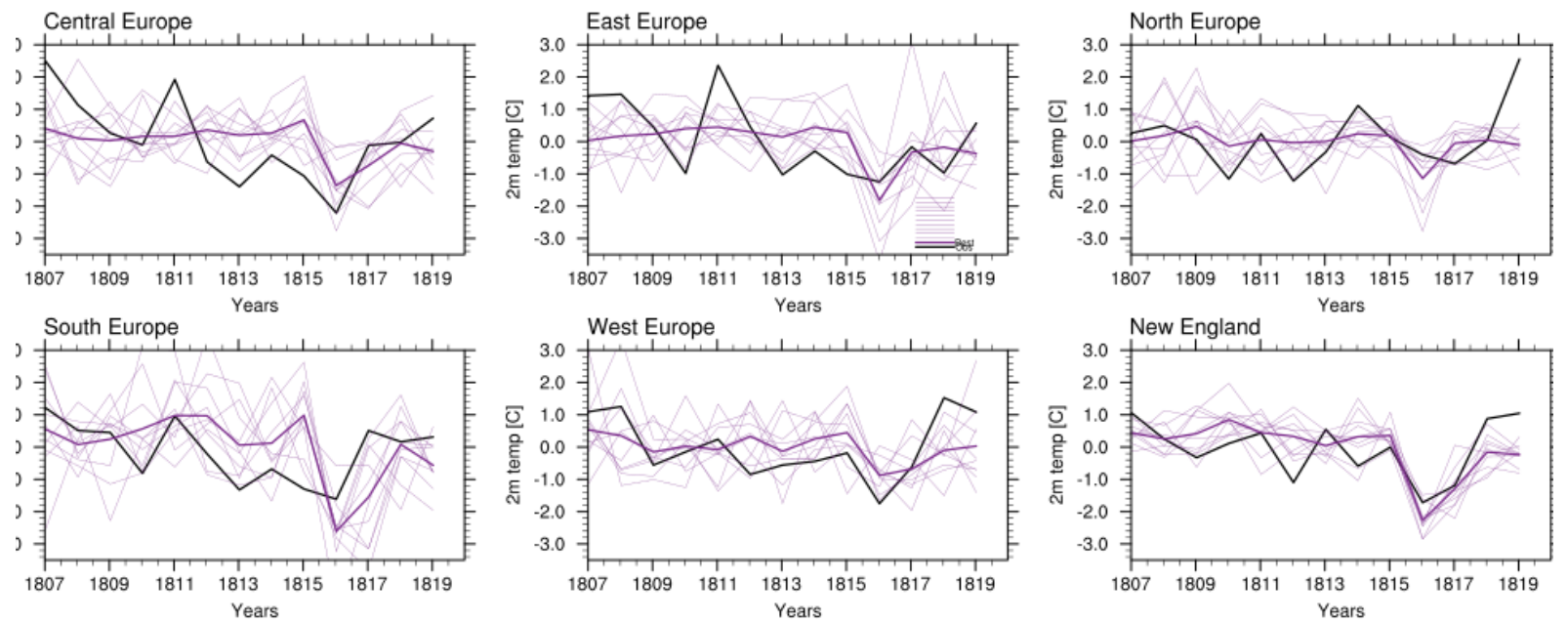

Figure S6. Same as Figure S3 but for $n N H P$ 

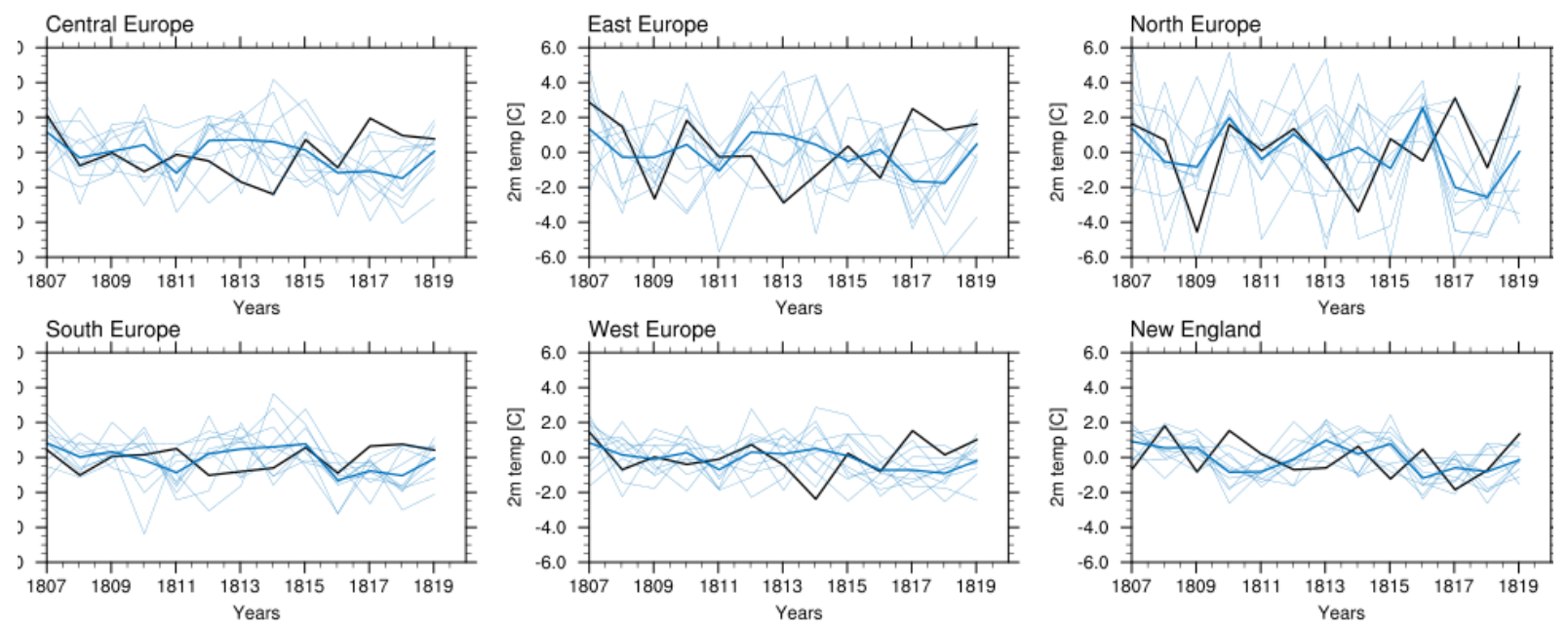

Figure S7. Same as Figure S3 but for seasonal mean near-surface NH winter temperature anomalies $\left({ }^{\circ} \mathrm{C}\right)$. The year denotes the February month
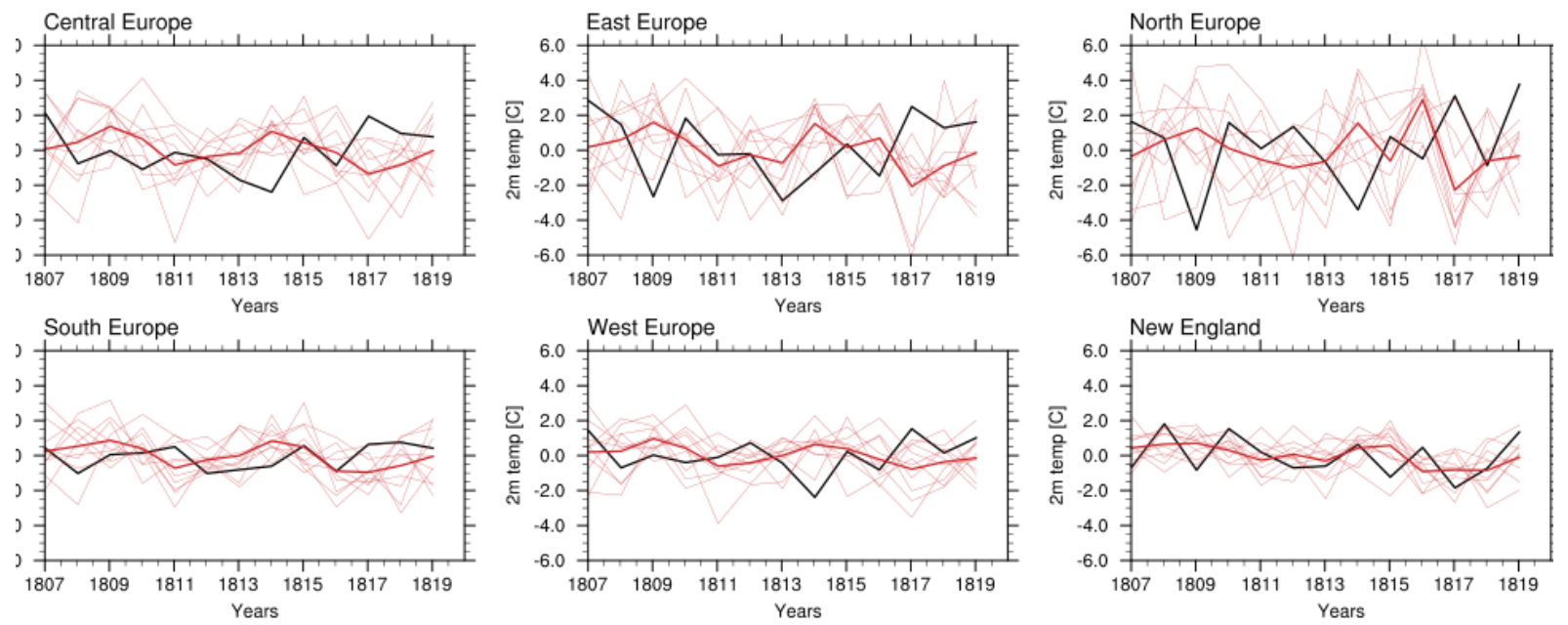

Figure S8. Same as Figure S4 but for seasonal mean near-surface NH winter temperature anomalies $\left({ }^{\circ} \mathrm{C}\right)$. The year denotes the February month. 

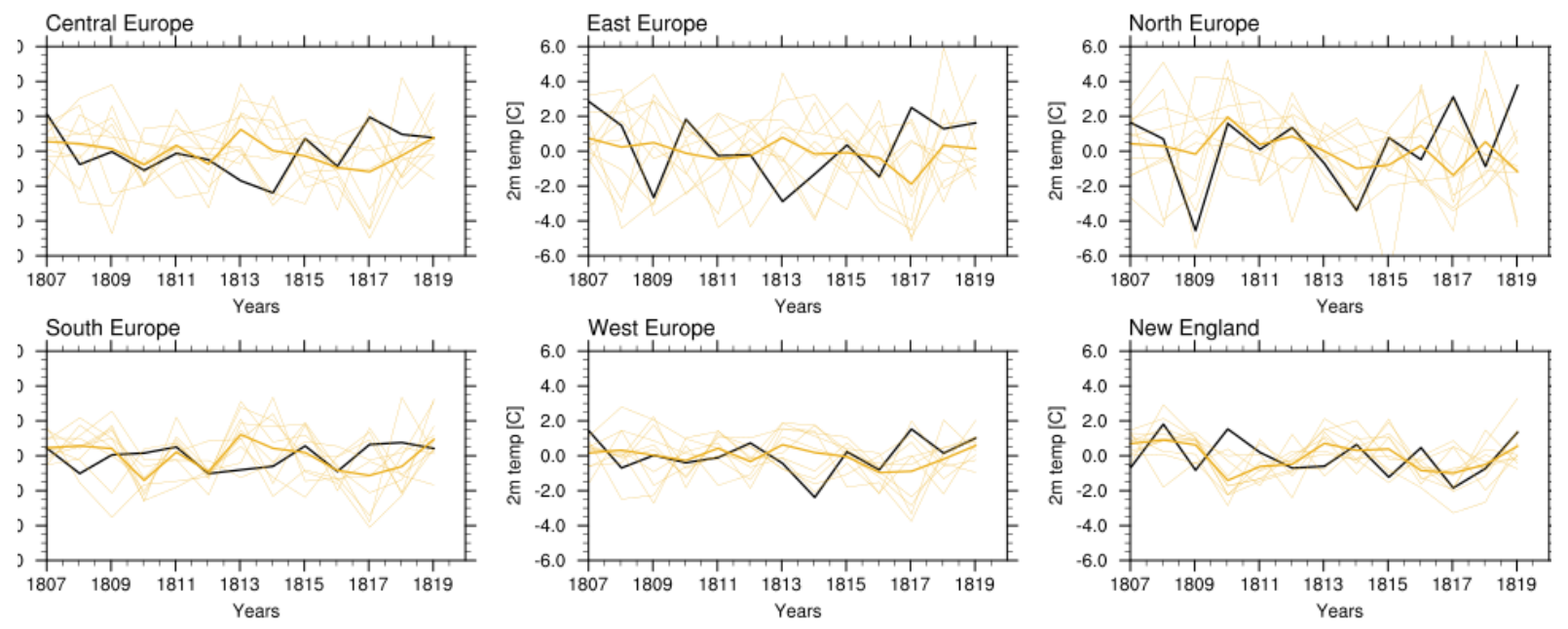

Figure S9. Same as Figure S5 but for seasonal mean near-surface NH winter temperature anomalies $\left({ }^{\circ} \mathrm{C}\right)$. The year denotes the February month.
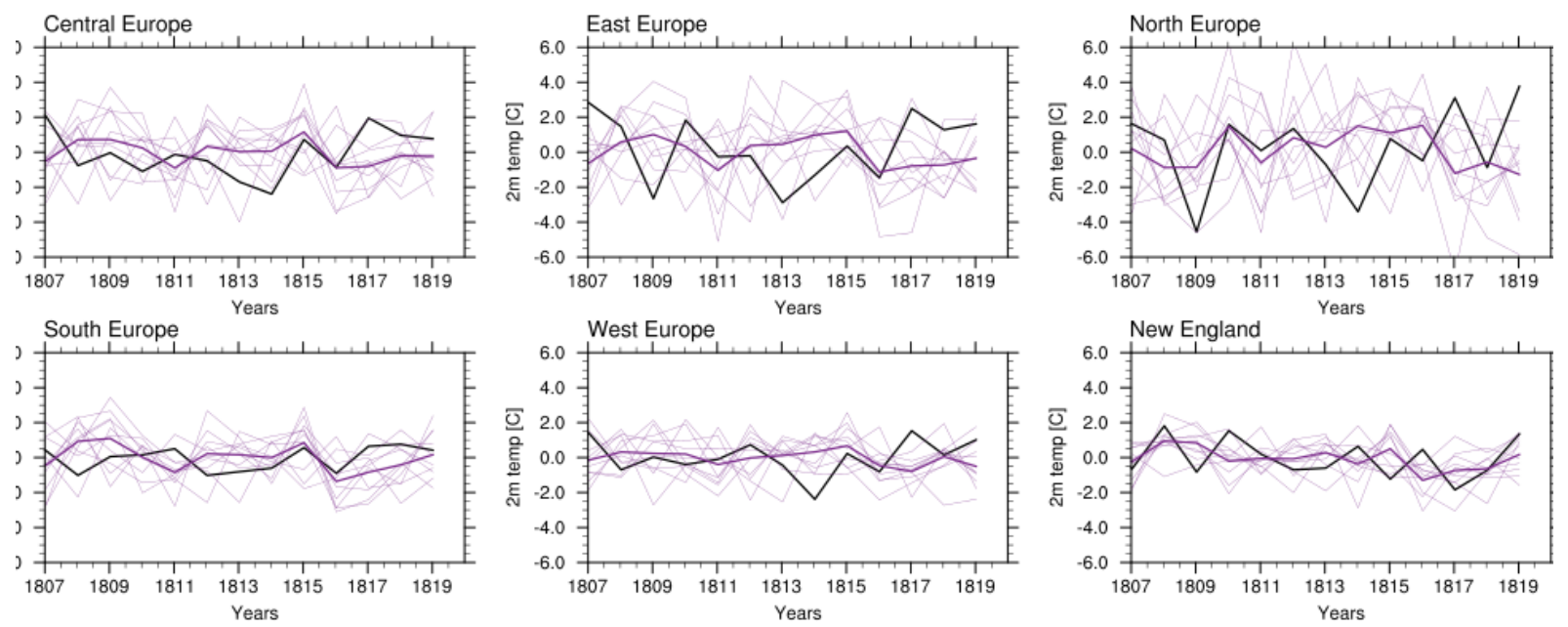

Figure S10. Same as Figure S5 but for seasonal mean near-surface NH winter temperature anomalies $\left({ }^{\circ} \mathrm{C}\right)$. The year denotes the February month. 


\section{References}

Thomason, L. W., Ernest, N., Millán, L., Rieger, L., Bourassa, A., Vernier, J.-P., Manney, G., Luo, B., Arfeuille, F., and Peter, T.: A global space-based stratospheric aerosol climatology: 1979-2016, Earth System Science Data, 10, 469-492, 2018. 